\title{
Group interventions to reduce emotional distress and fatigue in breast cancer patients: a 9-month follow-up pragmatic trial
}

\author{
Charlotte Grégoire ${ }^{\star 1,7}$, Isabelle Bragard ${ }^{2,7}$, Guy Jerusalem ${ }^{3}$, Anne-Marie Etienne ${ }^{1}$, Philippe Coucke ${ }^{4}$, \\ Gilles Dupuis ${ }^{5}$, Dominique Lanctôt ${ }^{5}$ and Marie-Elisabeth Faymonville ${ }^{6}$ \\ ${ }^{1}$ Health Psychology Department, University of Liege, Liege 4000, Belgium; ${ }^{2}$ Public Health Department, University of Liege, Liege \\ 4000, Belgium; ${ }^{3}$ Medical Oncology Department, CHU Liege, Liege 4000, Belgium; ${ }^{4}$ Radiation Oncology Department, CHU Liege, \\ University of Liege, Liege 4000, Belgium; ${ }^{5}$ Psychology Department, University of Quebec at Montreal, Montreal, QC H2L 2C4, \\ Canada and ${ }^{6}$ Algology-Palliative Care Department, CHU Liege, University of Liege, Liege 4000, Belgium
}

Background: Long-term effects of psychosocial interventions to reduce emotional distress, sleep difficulties, and fatigue of breast cancer patients are rarely examined. We aim to assess the effectiveness of three group interventions, based on cognitive behavioural therapy (CBT), yoga, and self-hypnosis, in comparison to a control group at a 9-month follow-up.

Methods: A total of 123 patients chose to participate in one of the interventions. A control group was set up for those who agreed not to participate. Emotional distress, fatigue, and sleep quality were assessed before (T0) and after interventions (T1), and at 3-month (T2) and 9-month follow-ups (T3).

Results: Nine months after interventions, there was a decrease of anxiety $(P=0.000)$, depression $(P=0.000)$, and fatigue $(P=0.002)$ in the hypnosis group, and a decrease of anxiety $(P=0.024)$ in the yoga group. There were no significant improvements for all the investigated variables in the CBT and control groups.

Conclusions: Our results showed that mind-body interventions seem to be an interesting psychological approach to improve the well-being of breast cancer patients. Further research is needed to improve the understanding of the mechanisms of action of such interventions and their long-term effects on quality of life.

Cancer diagnosis and treatments have significant side effects: pain; physical dysfunction; fatigue; sleep disturbances; and hair loss (Ewertz and Jensen, 2011; Die Trill, 2013; Weis and Horneber, 2015), as they are associated with the concomitant psychological and emotional reactions such as anxiety, depression, and distress (Die Trill, 2013; Tojal and Costa, 2015; Hernández Blázquez and Cruzado, 2016). Given the extent of these negative psychosocial consequences, several group interventions have been evaluated to improve cancer patients' quality of life (Faller et al, 2013; de Vries and Stiefel, 2014; Mitchell et al, 2014). These programmes, especially those based on cognitive behavioural therapy (CBT), had benefits on both anxiety and depression after the intervention (Osborn et al, 2006; Groarke et al, 2013; Gudenkauf et al, 2015). Cognitive behavioural therapy is a 'time-sensitive, structured, present-oriented psychotherapy directed towards solving current problems and teaching clients skills to modify dysfunctional thinking and behaviour' (Beck Institute for Cognitive Behavior Therapy, 2016). A review showed that CBT interventions were related to short- and long-term effects on quality of life in cancer survivors, with only short-term effects on depression and anxiety

\footnotetext{
*Correspondence: C Grégoire; E-mail: ch.gregoire@ulg.ac.be

${ }^{7}$ These authors contributed equally to this work.
}

Received 8 May 2017; revised 22 August 2017; accepted 24 August 2017; published online 19 September 2017

(C) 2017 Cancer Research UK. All rights reserved 0007-0920/17 
(Osborn et al, 2006). Concerning breast cancer patients, Antoni et al (2009) showed that positive effects of CBT intervention for anxiety appeared to hold for the 12-month observation period, whereas Stagl et al (2015) showed that a cognitive behavioural stress management programme had positive effects on depression and quality of life up to 15 years. Finally, in their study, Howell et al (2013) identified several trials that effectively used CBT to increase sleep quality and decrease insomnia in cancer patients.

Mind-body interventions such as yoga and hypnosis have also been studied in oncology settings (Mendoza et al, 2016), mostly in breast cancer patients. Yoga includes various fields such as ethical disciplines, physical postures, and spiritual practices with the aim of uniting mind and body (Smith and Pukall, 2009), whereas hypnosis is defined as 'a procedure during which a health professional or researcher suggests that a patient or subject experience changes in sensations, perceptions, thoughts, or behaviour' (The Executive Committee of the American Psychological Association - Division of Psychological Hypnosis, 1994). These mind-body approaches began to show short- and mid-term improvements in breast cancer patient fatigue, sleep, anxiety, and depressive symptoms (Banerjee et al, 2007; Moadel et al, 2007; Farrell-Carnahan et al, 2010; Mustian et al, 2013; Kiecolt-Glaser et al, 2014; Montgomery et al, 2014; Cramer et al, 2015; Lanctôt et al, 2016).

For example, Moadel et al (2007) have shown greater improvements in breast cancer patients at 3 months in the yoga group $v s$ a randomised control group for quality of life (QoL), emotional wellbeing, and distressed mood. In addition, Lanctôt et al (2016) demonstrated that compared to a waiting list control group, for which depressive symptoms increased during 8 weeks of chemotherapy, no similar increase was found in the yoga group. Kiecolt-Glaser et al (2014) have also shown in a randomised controlled 3-month trial for breast cancer patients that fatigue was reduced and vitality was increased for yoga participants compared to the control group. Groups did not differ on depression at any time. Finally, Mustian et al (2013) showed the efficacy of a yoga-based intervention to improve sleep quality of cancer survivors. However, Chandwani et al (2014) did not find any differences for mental health or sleep quality between yoga, stretching, or waiting control groups.

Concerning hypnosis, the study of Montgomery et al (2014) randomly assigned breast cancer patients to either CBT plus hypnosis $(\mathrm{CBTH})$ or an attention control group. They showed that the CBTH group had significantly lower levels of fatigue at the 6-month follow-up, but there was no measure for distress. A metaanalysis from Cramer et al (2015) also showed that several hypnosis-based interventions positively impacted fatigue and distress. Finally, an online self-hypnosis intervention for cancer survivors showed promising results in improving sleep (FarrellCarnahan et al, 2010). These initial results are encouraging, but there is still a lack of long-term data about the efficacy of yoga (Smith and Pukall, 2009) and hypnosis (Cramer et al, 2015).

Our article aims to present the results of a non-randomised study assessing the 9-month follow-up effects of three interventions (yoga, self-hypnosis, and CBT) in improving emotional distress, sleep quality, and fatigue in breast cancer patients. These three treatment plans will be compared to a control group, including patients who agreed not to participate in the interventions. For a better understanding of the evolution of the data, we will briefly present the short-term effects of the interventions (Bragard et al, 2017). We would like to test the hypothesis whether these effects persist over time.

\section{MATERIALS AND METHODS}

Patients and design. First, 114 patients with non-metastatic breast cancer were recruited up to 18 months after diagnosis (regardless of cancer stage and type of treatment received). They had to choose to participate in a yoga, a self-hypnosis, or a CBT group. We chose this kind of design because patients who receive their preferred treatment might be more motivated and could exhibit greater adherence to the treatment (King et al, 2005; Sedgwick, 2013). Moreover, Mills et al (2015) have already shown that there is not a major difference at baseline between the preference-based groups, as they are comparable even if they were not randomised. Fifteen of them dropped the study after one or two sessions (6 patients in the yoga group (22.2\%); 8 patients in the self-hypnosis group $(10.5 \%)$; and 1 patient in the CBT group (9.1\%)), leaving a final sample of 99 patients $\left(N_{\text {yoga }}=21 ; N_{\text {self-hypnosis }}=62 ; N_{\mathrm{CBT}}=10\right)$. Twenty-four patients were also recruited a second time to form a control group (Figure 1), with the final sample including 123 patients. Inclusion criteria were $\geqslant 18$ years old and ability to read, write, and speak French. Patients with a diagnosed psychiatric disorder or dementia were excluded. After giving written informed consent, participants completed a baseline assessment, including self-reported measures (T0). Three follow-up assessments were conducted 1 week (T1), 3 months (T2), and 9 months (T3) after the group intervention lasting between 2 and 3 months. For a feasibility issue, the control group completed questionnaires three times only: at T0; T1; and T3. This paper will focus on the data from the last follow-up (T3), but we will briefly present the results from $\mathrm{T} 1$ to give more information about the evolution of the data. Table 1 shows the principal demographics and medical data of these patients in each group at baseline.

Interventions. Yoga intervention included six weekly $90 \mathrm{~min}$ sessions in groups of 3-8 participants, led by trained teachers and developed in Montréal, QC, Canada (Lanctôt et al, 2010). The Bali Yoga Program-Breast Cancer (based on Hatha yoga) was specifically designed for breast cancer patients. Each participant received a DVD to encourage home practice. More details about the intervention can be found in Bragard et al (2017).

Self-hypnosis/self-care intervention included 6 sessions of 120 min every 2 weeks in groups of 3-8 participants. This was developed and led by one of the authors (MEF), an anaesthetist with experience in oncology who was also trained in hypnosis (Faymonville et al, 2010). It is a negotiating approach that fosters shared decision-making through tasks on general well-being rather than the health problem itself. At the end of the session, a $15 \mathrm{~min}$ hypnosis exercise was conducted. They received CDs with the hypnosis exercises and homework assignments between sessions (Vanhaudenhuyse et al, 2015). More details are given in Bragard et al (2017).

Cognitive behavioural therapy intervention included 6 weekly 90 min sessions in groups of 3-8 participants led by CBT-trained psychologists with experience in psycho-oncology. This programme was developed by team leaders (AME, IB, and MD) and modelled on the work of Andersen et al (2009) and Savard (2010). Relaxation training took place at the end of each session and participants performed tasks between sessions. More details about the intervention are given in Bragard et al (2017).

The control group included patients who agreed not to attend any of the groups. They continued to benefit from their usual care throughout the duration of the study.

Measures. The following measures were contained in the assessment battery.

Demographics and medical history. A questionnaire looking at age, marital status, education, and cancer-related variables (e.g., treatment types) was completed.

The Hospital Anxiety Depression Scale. The Hospital Anxiety Depression Scale (HADS) is a reliable and validated 14-item measure assessing anxiety and depression in physically ill subjects. 


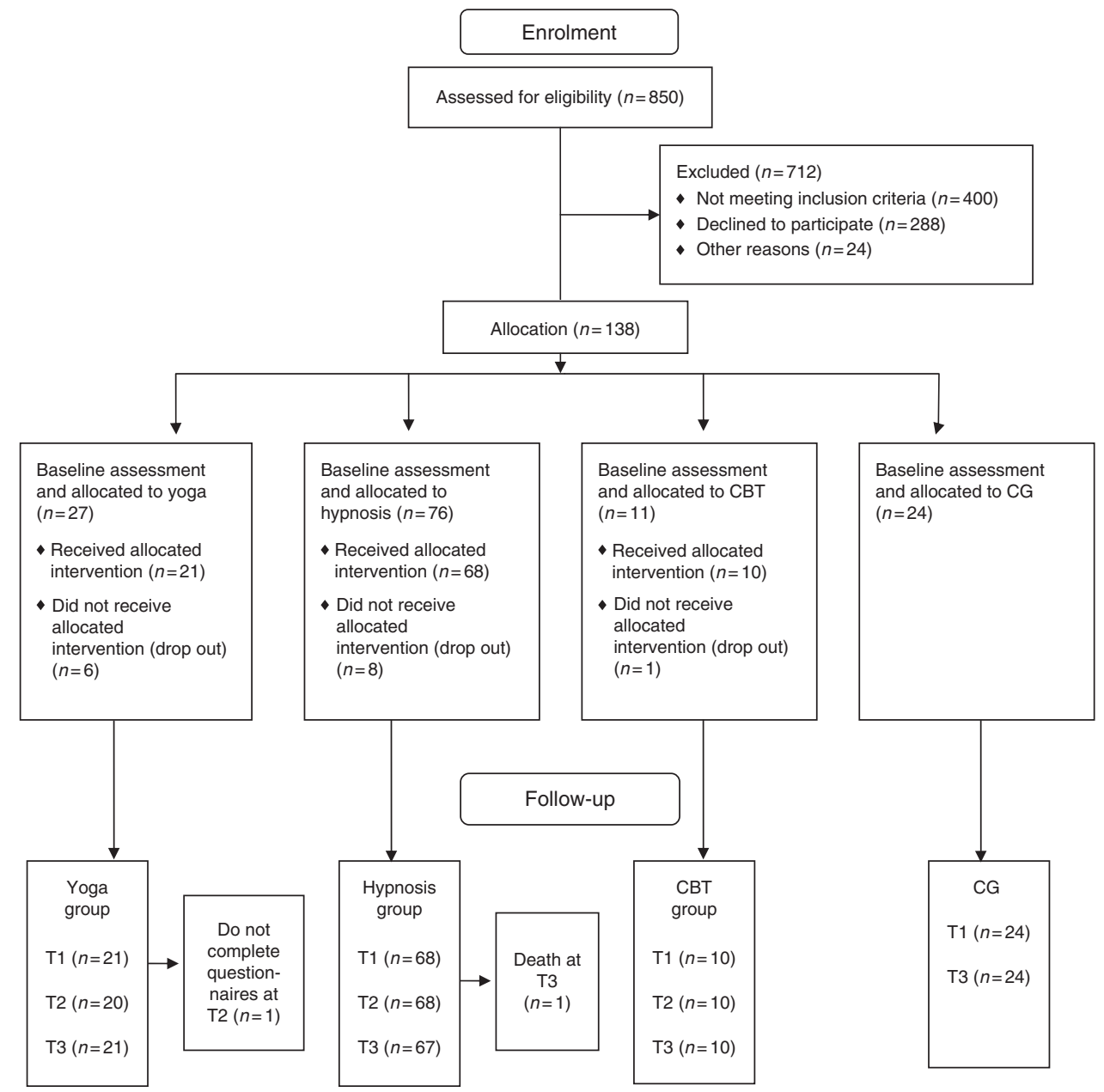

Figure 1. Flow of study participants.

Seven items for anxiety and 7 for depression are rated on a 4-point Likert scale $(0=$ symptoms not present to $3=$ symptoms considerable). Each subscale was scored from 0 to 21 (0-7: 'normal range;' 8-10: 'borderline;' or 11-21: 'probable presence of anxiety or depressive disorder') (Zigmond and Snaith, 1983).

European Organization for Research and Treatment of CancerQoL Core Questionnaire-30. The core questionnaire (30 items) to assess the QoL of cancer patients incorporates five functional scales, three symptom scales, a global health status/QoL scale, and several single items for additional symptoms and the perceived financial impact of the disease. The responses indicate the extent to which the patient experienced symptoms or problems. Each item is scored on a 4-point Likert scale ('not at all' to 'very much'), excepted for the global health status/QoL that is a 7-point scale ('very bad' to 'excellent') (Aaronson et al, 1993). In this paper, we only discuss the fatigue-related items of this questionnaire (3 items).

Insomnia Severity Index. (Savard et al, 2005) This is a 7-item measure of subjective sleep complaints and associated distress. Items are scored on a 5-point Likert scale, ranging from 0 to 4 with higher total scores representing more severe insomnia symptoms. The cutoff scores are $0-7$ (no clinically significant sleep difficulties), 7-14 (sleep difficulties warranting further investigation), and $15+$ (presence of clinically significant insomnia).

The data collected from these questionnaires are displayed in Table 2.
Outcomes. The outcome measures assessed the 9-month followup effects of three interventions for breast cancer patients' emotional distress (anxiety and depression), fatigue, and sleep difficulties, to then compare the three intervention groups with the control group.

Data analysis. Baseline (T0) demographic, medical, and psychological data were compared between groups to test for initial group equivalency with ANOVA and $\chi^{2}$-tests. To be considered for data analysis, patients attended at least three sessions and completed the first (T0) and last assessments (T3).

Group-by-time changes in emotional distress, fatigue, and sleep difficulties were processed using multivariate analysis of variance with repeated measures, followed by post hoc comparisons (Tukey's HSD test). All tests were two-tailed and the alpha was set at 0.05 .

\section{RESULTS}

Of the 123 women in the intervention or control groups, 1 patient died in the hypnosis group. Thus, in that group, there were data at T0 and T3 for 67 patients; in the yoga group, there were data at T0 and T3 for 21 patients; in the CBT group, there were data at T0 and T3 for 10 patients; and in the control group, there were data at T0 and T3 for 24 patients (Figure 1). The four groups did not differ at baseline on demographics, medical history, psychological variables (anxiety, depression, fatigue, and sleep quality), or number of sessions (for each group). The average attendance rate was 5.8 sessions for yoga, 5.4 for self-hypnosis, and 5.7 for CBT. 
Table 1. Baseline patient's demographics data and medical history in each group

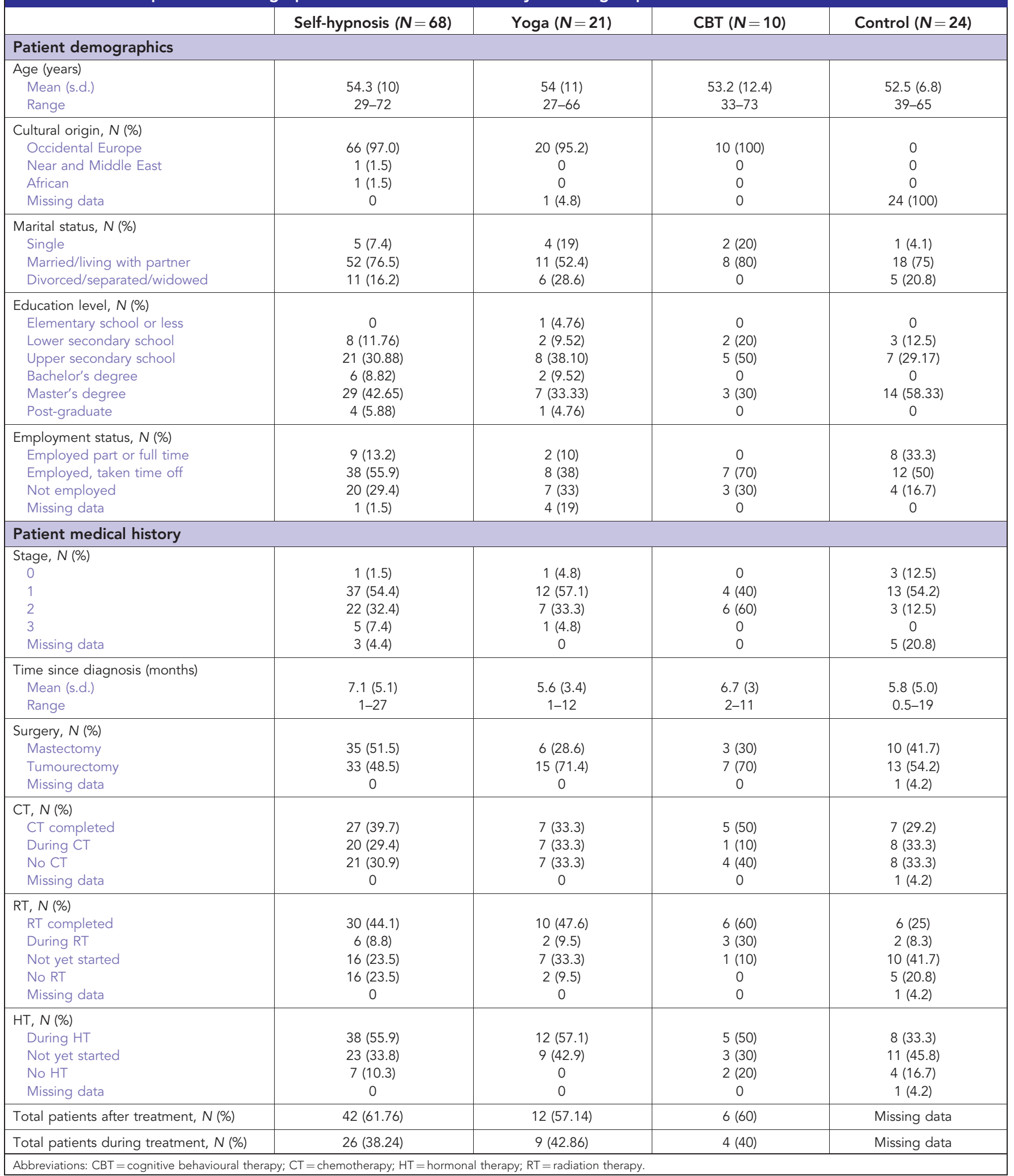

Impact of interventions on emotional distress, fatigue, and sleep quality at T1 and T3. To present the evolution of the data between T0 and T1, we conducted a multivariate analysis of the psychological variables with repeated measures on time of evaluation. No significant effect by group and no significant group-by-time interaction effect were revealed, but a significant effect of time of the evaluation appeared $(\wedge=0.862 ; \mathrm{F}(4)=4.59$;
$\left.P=0.002 ; \eta_{p}^{2}=0.14\right)$. Post hoc comparisons revealed a decrease of anxiety $(P=0.000)$, depression $(P=0.004)$, and fatigue $(P=0.045)$ in the hypnosis group, and a decrease of anxiety $(P=0.010)$ in the yoga group.

Another multivariate analysis of the psychological variables with repeated measures on time of evaluation (between T0 and T3) indicated no significant effect by group, except for a significant 
Table 2. Mean baseline and follow-up scores in different outcomes by group

\begin{tabular}{|c|c|c|c|c|c|}
\hline & TO & T1 & Evolution T0-T1 & T3 & Evolution TO-T3 \\
\hline & Mean (s.d.) & Mean (s.d.) & $P$ & Mean (s.d.) & $P$ \\
\hline \multicolumn{6}{|c|}{ Self-hypnosis $(N=68)$} \\
\hline Anxiety & $8.68(4.12)$ & $6.70(3.58)$ & 0.000 & $6.39(3.49)$ & 0.000 \\
\hline Depression & $5.06(3.17)$ & $3.84(3.01)$ & 0.004 & $3.15(2.87)$ & 0.000 \\
\hline EORTC QLQ C & & & & & \\
\hline Fatigue & $2.59(0.78)$ & $2.34(0.65)$ & 0.045 & $2.18(0.67)$ & 0.002 \\
\hline HADS & & & & & \\
\hline Anxiety & $9.76(4.62)$ & 7.05 (3.35) & 0.010 & $6.67(2.48)$ & 0.024 \\
\hline Depression & $5.24(3.74)$ & $3.90(3.03)$ & 0.260 & $3.14(2.90)$ & 0.063 \\
\hline EORTC QLQ C & & & & & \\
\hline Fatique & $2.44(0.74)$ & $2.38(0.90)$ & 0.999 & $2.00(0.63)$ & 0.442 \\
\hline$|S|$ & $12.76(6.91)$ & $11.05(6.26)$ & 0.868 & $8.45(5.15)$ & 0.089 \\
\hline EORTC QLO C & & & & & \\
\hline Fatigue & $2.20(0.65)$ & $2.07(0.49)$ & 0.999 & $2.07(0.52)$ & 0.999 \\
\hline IS| & $12.30(5.74)$ & $11.50(5.44)$ & 0.999 & $11.70(6.07)$ & 0.999 \\
\hline \multicolumn{6}{|c|}{ Control $(N=24)$} \\
\hline \multicolumn{6}{|c|}{ HADS } \\
\hline Anxiety & $7.17(2.96)$ & $7.58(3.40)$ & 0.999 & $8.17(4.03)$ & 0.910 \\
\hline Depression & 4.13 (3.72) & $4.04(3.00)$ & 1.00 & $3.96(3.76)$ & 0.999 \\
\hline \multicolumn{6}{|c|}{ EORTC QLQ C30 } \\
\hline Fatigue & $2.56(0.92)$ & $2.36(0.74)$ & 0.844 & $2.36(0.74)$ & 0.923 \\
\hline$|S|$ & $10.54(6.73)$ & $12.00(5.54)$ & 0.916 & $10.96(5.82)$ & 0.999 \\
\hline
\end{tabular}

effect of time of the evaluation $(\wedge=0.795 ; \mathrm{F}(4)=7.23 ; P=0.000$; $\left.\eta_{p}^{2}=0.21\right)$, and a significant group-by-time interaction effect $\left(\wedge=0.830 ; \mathrm{F}(12)=1.80 ; P=0.047 ; \eta_{p}^{2}=0.07\right)$. Post hoc comparisons revealed a decrease of anxiety $(P=0.000)$; depression $(P=0.000)$, and fatigue $(P=0.002)$ in the hypnosis group, as well as a decrease of anxiety $(P=0.024)$ in the yoga group. There were no significant improvements for all the investigated variables in the CBT and control groups.

The graphic evolution of the results over time in each group is displayed in Figure 2. We can see that in each experimental group, different variables improved over time, as their means decreased, even though some effects are not significant.

\section{DISCUSSION}

This non-randomised study assessed the 9-month follow-up effects of three interventions (yoga, self-hypnosis, and CBT) in improving emotional distress, fatigue, and sleep quality in breast cancer patients.

In all, 99 breast cancer patients participated in the interventions: 68 in the hypnosis group (1 patient died); 21 in the yoga group; and 10 in the CBT group, while 24 participated as a control group. The number of participants in the hypnosis group has been previously discussed (Bragard et al, 2017) and could be explained in terms of the notoriety of the trainer, and the greater availability of yoga or individual psychological counselling outside the hospital compared to self-hypnosis. Patients' demographic, medical, and psychological characteristics were homogenous in the four groups at baseline.

In the self-hypnosis group, there were improvements 9 months after the intervention for anxiety, depression, and fatigue. In the yoga group, anxiety also decreased at the 9-month follow-up. Given the lack of long-term results regarding the efficacy of mindbody interventions in oncology settings, it is difficult to contrast our results with existing ones. However, we see that they contrast with those of Chandwani et al (2014), who found no effect of yoga after 6 months on breast cancer patients' emotional or mental health, but positive effects of yoga on fatigue at a 6-month followup, as did several other authors at a 3-month follow-up (Bower et al, 2011, 2012; Derry et al, 2014; Kiecolt-Glaser et al, 2014). Our results are congruent with those of Banerjee et al (2007) who found a positive impact of yoga on anxiety in breast cancer patients undergoing radiotherapy. Concerning hypnosis, our results contrast with those of Jensen et al (2012) who found no effect of an hypnosis-based intervention on anxiety at a 6-month follow-up, but are congruent with the study of Montgomery et al (2014), where CBTH created lower levels of fatigue at a 6-month followup. Despite the fact that we did not investigate the effects of our intervention later than at 9-month follow-up, our study seems to give a first argument in favour of a long-term effect of alternative psychotherapeutic approaches, especially hypnosis, as part of selfcare intervention for emotional distress and fatigue in breast cancer patients.

We found no improvement in the CBT group after 9 months. These results contrast with the review of Osborn et al (2006), showing that CBT interventions were related to short-term effects on depression and anxiety in cancer survivors, but they are congruent with those of Groarke et al (2013) and Boesen et al (2011), who did not find long-term effect on distress in their studies. Considering our results, we concluded that the two mindbody interventions led to better outcomes than the control and CBT did, especially self-hypnosis in terms of improvement of emotional distress and fatigue. The two mind-body interventions were also the only ones to lead to positive results immediately after 

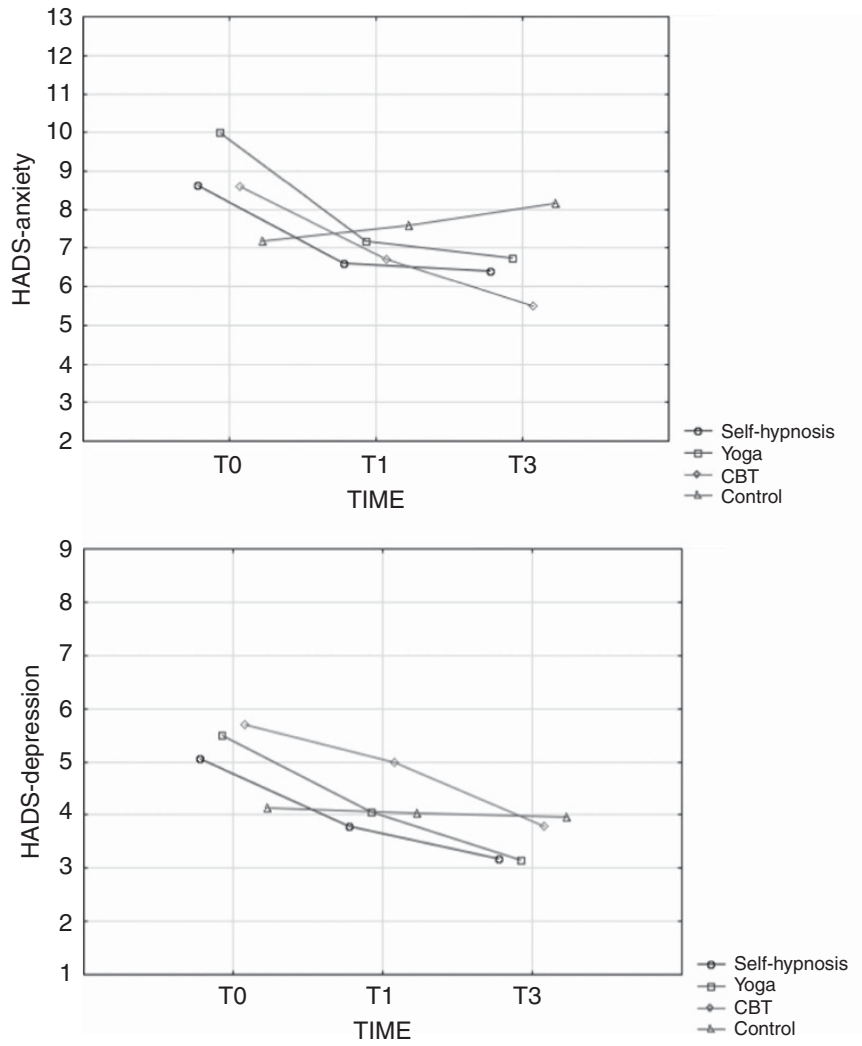

Figure 2. Graphic evolution of the data over time.

the group. More specifically, 1 week after the intervention, emotional distress and fatigue improved in the hypnosis group, whereas anxiety improved in the yoga group. These results suggest that self-hypnosis is a powerful tool to improve well-being quickly.

To explain these differences between the interventions, we can focus on the mechanisms of change of these different techniques. On one hand, mind-body techniques in general focus on balancing the autonomic nervous system by activating its parasympathetic branch, to reduce the physiological response to stress. Indeed, mind and body seem to constantly communicate in a bidirectional way (Sawni and Breuner, 2017). Yoga is known to reduce expressive suppression (Dick et al, 2014) and to develop calmness (Sherman et al, 2013) and mindfulness, which increases attention regulation, body awareness, and emotion regulation. These mechanisms can help to decrease patients' anxiety. Hypnosis has three major components, which can influence cognition and emotional regulation: absorption, which is the involvement in a perceptual, imaginative, or ideational experience; dissociation, which is the mental separation of different components of experience that would usually be processed as a whole; and suggestibility, which is the responsiveness to social clues, enhancing the propensity to comply with hypnotic instructions and suspending critical judgment (Vanhaudenhuyse et al, 2014). Those hypnotic suggestions also facilitate mind-body connection and lead to physical, emotional, and behavioural changes (Sawni and Breuner, 2017), which could explain the impact of that intervention on patients' emotional distress and fatigue. On the other hand, CBT does not directly address the body, as it focuses on emotion, cognition, and behaviour. This fundamental difference between the techniques used could explain the differences in our results, especially given the fact that our participants were oncologic patients, all suffering from physical difficulties linked to their cancer. The fact that the body is very impacted by the disease could explain why mind-body approaches are so pertinent and beneficial for such patients.
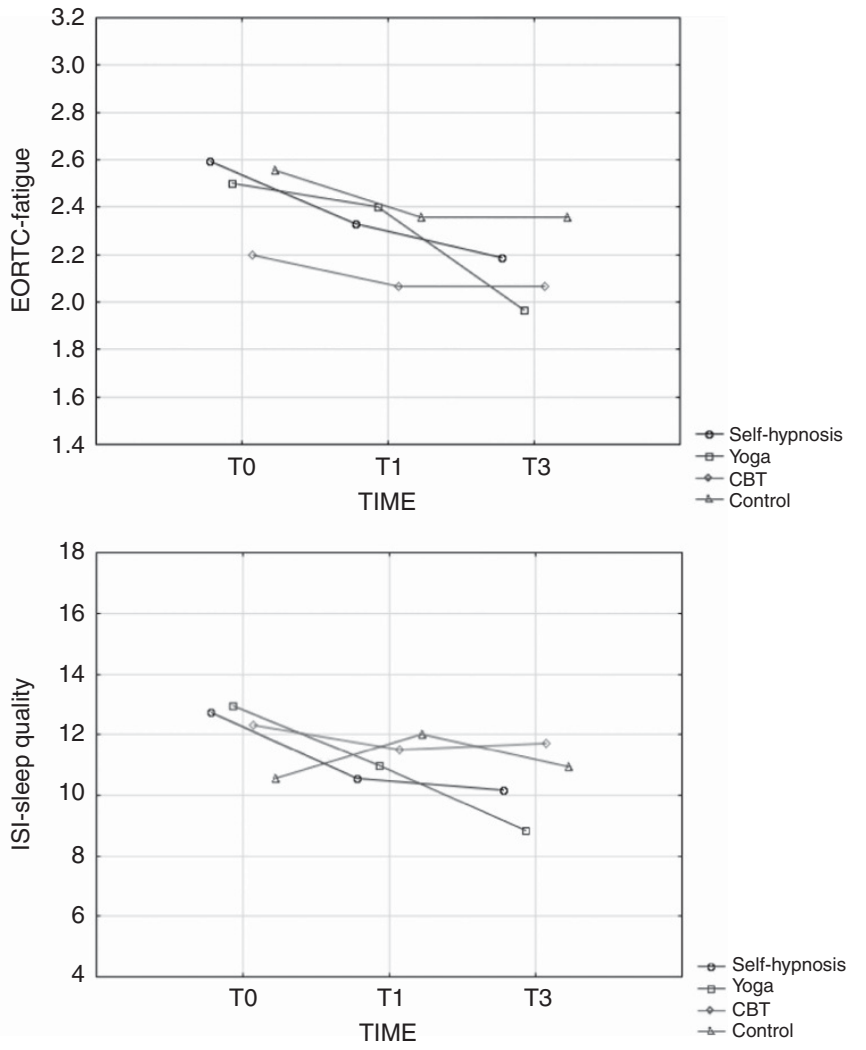

There are some limitations of this study. First, the small number of participants in the yoga, CBT, and control groups requires caution in interpreting the findings, as well as the fact that the number of participants in the self-hypnosis group was significantly higher than in the other groups. Second, our study was not randomised but included a control group to compare to the intervention groups. However, it is likely that patient interest, driving the intensity of practice and its enjoyment, has a positive role (Carlson and Bultz, 2008). Carlson et al (2014) showed in a randomised study that patient preference was a strong predictor of outcomes. In their study comparing two active psychosocial interventions in a control group, breast cancer patients who were assigned to their preferred intervention reported significantly greater improvement in QoL compared to women who received their non-preferred intervention. Another limitation is that the control group did not benefit from the intervention at all in our study. Indeed, even if they agreed not to participate, the interventions proposed could have been positive for them and it seems important to figure out how to motivate such patients to engage in the process. In addition, participants in the control group did not complete all the questionnaires for feasibility reasons, which limits some analyses. Finally, we were only able to assess the effects of the intervention at a 9-month follow-up, despite the fact that more and more studies collect data over longer periods of time.

Future research might investigate the associations between the variables discussed by adopting an experimental design, such as a randomised-controlled trial, which is the most scientifically rigorous trial design for assessing the efficacy of an intervention (Pocock, 1983; Millat et al, 2005), and by collecting data during longer periods of time. Larger sample sizes would also help measure more significant effects. Future research might include all types of cancer, not only breast cancer, and some objective measures of emotion regulation and sleep quality such as cardiac frequency, activity, or sleep pattern monitoring. At a clinical level, 
our study highlights a need to consider the psychological impact of cancer and proposes different interventions to help patients cope with it. Our study strongly argues in favour of alternative psychotherapeutic approaches, especially hypnosis-based interventions, to improve fatigue and emotional distress. As patients are interested in those kinds of therapeutic interventions, increasing our knowledge about them and their mechanisms; thus, proposing them in an appropriate way in the oncology care routine could be very useful both for health professionals and patients.

In conclusion, this study showed the benefits of self-hypnosis in improving anxiety, depression, and fatigue of breast cancer patients immediately after the intervention and until the 9-month followup. Yoga also seems to be useful in decreasing anxiety quickly after the intervention, with this effect lasting at least 9 months. Larger samples would be necessary to determine differences between the three types of interventions.

\section{ACKNOWLEDGEMENTS}

This work was supported by the 'Plan National Cancer' of Belgium (Grant number 137). We are grateful to all the patients who participated in the study. We also thank the yoga teachers (R Blauwaert, J Van Brabant, and D Dubois), the yoga trainer from Montreal (A Anestin), the psychologists (I Willems, B Brouette, C Jourdan, and A Wagener), the data managers (I Jupsin and $S$ Uccello), and the psychology students (S Coudert and $\mathrm{M}$ Beaupain). All procedures performed in this study were in accordance with the ethical standards of the institutional and national research committee and with the 1964 Helsinki declaration and its later amendments or comparable ethical standards. The study was approved by the Institutional Ethics Board 'Comité d'éthique Hospitalo-Facultaire Universitaire de Liège' (B707201215157), with each participant providing written consent.

\section{CONFLICT OF INTEREST}

The authors declare no conflict of interest.

\section{AUTHOR CONTRIBUTIONS}

IB and CG participated in the conception and design of the study, in the acquisition and interpretation of data, and in drafting the manuscript. A-ME, M-EF, PC, GD, DL, and GJ participated in the conception and design of the study, in the interpretation of data, and in revising the manuscript critically for important intellectual content. All authors read and approved the final manuscript, and agree to be accountable for all aspects of the work in ensuring that questions related to the accuracy or integrity of any part of the work are appropriately investigated and resolved.

\section{REFERENCES}

Aaronson NK, Ahmedzai S, Bergman B, Bullinger M, Cull A, Duez NJ, Filiberti A, Flechtner H, Fleishman SB, de Haes JC (1993) The European Organization for Research and Treatment of Cancer QLQ-C30: a qualityof-life instrument for use in international clinical trials in oncology. $J$ Natl Cancer Inst 85: 365-376.

Andersen BL, Golden-Kreutz DM, Emery CF, Thiel DL (2009) Biobehavioral intervention for cancer stress: conceptualization, components, and intervention strategies. Cogn Behav Pract 16: 253-265.

Antoni MH, Lechner S, Diaz A, Vargas S, Holley H, Phillips K, McGregor B, Carver CS, Blomberg B (2009) Cognitive behavioral stress management effects on psychosocial and physiological adaptation in women undergoing treatment for breast cancer. Brain Behav Immun 23: 580-591. Banerjee B, Vadiraj HS, Ram A, Rao R, Jayapal M, Gopinath KS, Ramesh BS, Rao N, Kumar A, Raghuram N, Hegde S, Nagendra HR, Prakash Hande M (2007) Effects of an integrated yoga program in modulating psychological stress and radiation-induced genotoxic stress in breast cancer patients undergoing radiotherapy. Integr Cancer Ther 6: 242-250.

Beck Institute for Cognitive Behavior Therapy (2016) What is cognitive behavior therapy (CBT)? Available at: https://www.beckinstitute.org/getinformed/what-is-cognitive-therapy/.

Boesen EH, Karlsen R, Christensen J, Paaschburg B, Nielsen D, Bloch IS, Christiansen B, Jacobsen K, Johansen C (2011) Psychosocial group intervention for patients with primary breast cancer: a randomised trial. Eur J Cancer 47: 1363-1372.

Bower JE, Garet D, Sternlieb B (2011) Yoga for persistent fatigue in breast cancer survivors: results of a pilot study. Evid Based Complement Alternat Med 2011: 1-8.

Bower JE, Garet D, Sternlieb B, Ganz PA, Irwin MR, Olmstead R, Greendale G (2012) Yoga for persistent fatigue in breast cancer survivors: a randomized controlled trial. Cancer 118: 3766-3775.

Bragard I, Etienne A-M, Faymonville M-E, Coucke P, Lifrange E, Schroeder H, Wagener A, Dupuis G, Jerusalem G (2017) A nonrandomized comparison study of self-hypnosis, yoga, and cognitivebehavioral therapy to reduce emotional distress in breast cancer patients. Int J Clin Exp Hypn 65: 189-209.

Carlson LE, Bultz BD (2008) Mind-body interventions in oncology. Curr Treat Options Oncol 9: 127-134.

Carlson LE, Tamagawa R, Stephen J, Doll R, Faris P, Dirkse D, Speca M (2014) Tailoring mind-body therapies to individual needs: patients' program preference and psychological traits as moderators of the effects of mindfulness-based cancer recovery and supportive-expressive therapy in distressed breast cancer survivors. JNCI Monogr 2014: 308-314.

Chandwani KD, Perkins G, Nagendra HR, Raghuram NV, Spelman A, Nagarathna R, Johnson K, Fortier A, Arun B, Wei Q, Kirschbaum C, Haddad R, Morris GS, Scheetz J, Chaoul A, Cohen L (2014) Randomized, controlled trial of yoga in women with breast cancer undergoing radiotherapy. J Clin Oncol Off J Am Soc Clin Oncol 32: 1058-1065.

Cramer H, Lauche R, Paul A, Langhorst J, Kummel S, Dobos GJ (2015) Hypnosis in breast cancer care: a systematic review of randomized controlled trials. Integr Cancer Ther 14: 5-15.

de Vries M, Stiefel F (2014) Psycho-oncological interventions and psychotherapy in the oncology setting. Psycho-Oncology. In: Goerling U (ed). Springer: Berlin, Heidelberg, pp 121-135.

Derry HM, Jaremka LM, Bennett JM, Peng J, Andridge R, Shapiro C, Malarkey WB, Emery CF, Layman R, Mrozek E, Glaser R, Kiecolt-Glaser JK (2014) Yoga and self-reported cognitive problems in breast cancer survivors: a randomized controlled trial. Psychooncology 24: 958-966.

Dick AM, Niles BL, Street AE, DiMartino DM, Mitchell KS (2014) Examining mechanisms of change in a yoga intervention for women: the influence of mindfulness, psychological flexibility, and emotion regulation on PTSD symptoms. J Clin Psychol 70: 1170-1182.

Die Trill M (2013) Anxiety and sleep disorders in cancer patients. EJC Suppl 11: 216-224.

Ewertz M, Jensen AB (2011) Late effects of breast cancer treatment and potentials for rehabilitation. Acta Oncol Stockh Swed 50: 187-193.

Faller H, Schuler M, Richard M, Heckl U, Weis J, Kuffner R (2013) Effects of psycho-oncologic interventions on emotional distress and quality of life in adult patients with cancer: systematic review and meta-analysis. J Clin Oncol 31: 782-793.

Farrell-Carnahan L, Ritterdband LM, Bailey ET, Thorndike FP, Lord HR, Baum LD (2010) Feasibility and preliminary efficacy of a self-hypnosis intervention available on the web for cancer survivors with insomnia. Electron J Appl Psychol 6: 10-23.

Faymonville ME, Bejenke C, Hansen E (2010) Hypnotic techniques. In Handbook of Communication in Anesthesia and Critical Care. Allan M Cyna: Oxford, UK, pp 249-261.

Groarke A, Curtis R, Kerin M (2013) Cognitive-behavioural stress management enhances adjustment in women with breast cancer. $\mathrm{Br} \mathrm{J}$ Health Psychol 18: 623-641.

Gudenkauf LM, Antoni MH, Stagl JM, Lechner SC, Jutagir DR, Bouchard LC, Blomberg BB, Glück S, Derhagopian RP, Giron GL, Avisar E, TorresSalichs MA, Carver CS (2015) Brief cognitive-behavioral and relaxation 
training interventions for breast cancer: a randomized controlled trial. J Consult Clin Psychol 83: 677-688.

Hernández Blázquez M, Cruzado JA (2016) A longitudinal study on anxiety, depressive and adjustment disorder, suicide ideation and symptoms of emotional distress in patients with cancer undergoing radiotherapy. J Psychosom Res 87: 14-21.

Howell D, Oliver TK, Keller-Olaman S, Davidson J, Garland S, Samuels C, Savard J, Harris C, Aubin M, Olson K, Sussman J, Macfarlane J, Taylor C, Sleep Disturbance Expert Panel on behalf of the Cancer Journey Advisory Group of the Canadian Partnership Against Cancer (2013) A PanCanadian practice guideline: prevention, screening, assessment, and treatment of sleep disturbances in adults with cancer. Support Care Cancer Off J Multinatl Assoc Support Care Cancer 21: 2695-2706.

Jensen MP, Gralow JR, Braden A, Gertz KJ, Fann JR, Syrjala KL (2012) Hypnosis for symptom management in womenwith breast cancer: a pilot study. Int J Clin Exp Hypn 60: 135-159.

Kiecolt-Glaser JK, Bennett JM, Andridge R, Peng J, Shapiro CL, Malarkey WB, Emery CF, Layman R, Mrozek EE, Glaser R (2014) Yoga's impact on inflammation, mood, and fatigue in breast cancer survivors: a randomized controlled trial. J Clin Oncol 32: 1040-1049.

King M, Nazareth I, Lampe F, Bower P, Chandler M, Morou M, Sibbald B, Lai R (2005) Impact of participant and physician intervention preferences on randomized trials: a systematic review. JAMA 293: 1089-1099.

Lanctôt D, Dupuis G, Anestin A, Bali M, Dubé P, Martin G (2010) Impact of the yoga bali method on quality of life and depressive symptoms among women diagnosed with breast cancer undergoing chemotherapy. Psychooncology 19(Suppl.2): 139.

Lanctôt D, Dupuis G, Marcaurell R, Anestin AS, Bali M (2016) The effects of the Bali Yoga Program (BYP-BC) on reducing psychological symptoms in breast cancer patients receiving chemotherapy: results of a randomized, partially blinded, controlled trial. J Complement Integr Med 13: 405-412. Mendoza ME, Capafons A, Gralow JR, Syrjala KL, Suárez-Rodríguez JM, Fann JR, Jensen MP (2016) Randomized controlled trial of the Valencia model of waking hypnosis plus CBT for pain, fatigue, and sleep management in patients with cancer and cancer survivors: Valencia model of waking hypnosis for managing cancer-related symptoms.

Psychooncology; e-pub ahead of print 28 July 2016; doi:10.1002/pon.4232.

Millat B, Borie F, Fingerhut A (2005) Patient's preference and randomization: new paradigm of evidence-based clinical research. World J Surg 29: 596-600.

Mills N, Khazragui H, Metcalfe C, Lane A, Davis M, Young G, Neal D, Hamdy F, Donovan J (2015) Do people who choose their treatment in a large randomised trial with parallel preference groups differ at baseline from those who agree to random treatment allocation? Results from the protect study. Trials 16: P109.

Mitchell SA, Hoffman AJ, Clark JC, DeGennaro RM, Poirier P, Robinson CB, Weisbrod BL (2014) Putting evidence into practice: an update of evidencebased interventions for cancer-related fatigue during and following treatment. Clin J Oncol Nurs 18: 38-58.

Moadel AB, Shah C, Wylie-Rosett J, Harris MS, Patel SR, Hall CB, Sparano JA (2007) Randomized controlled trial of yoga among a multiethnic sample of breast cancer patients: effects on quality of life. J Clin Oncol Off J Am Soc Clin Oncol 25: 4387-4395.

Montgomery GH, David D, Kangas M, Green S, Sucala M, Bovbjerg DH, Hallquist MN, Schnur JB (2014) Randomized controlled trial of a cognitive-behavioral therapy plus hypnosis intervention to control fatigue in patients undergoing radiotherapy for breast cancer. J Clin Oncol 32: 557-563.

Mustian KM, Sprod LK, Janelsins M, Peppone LJ, Palesh OG, Chandwani K, Reddy PS, Melnik MK, Heckler C, Morrow GR (2013) Multicenter, randomized controlled trial of yoga for sleep quality among cancer survivors. J Clin Oncol Off J Am Soc Clin Oncol 31: 3233-3241.

Osborn RL, Demoncada AC, Feuerstein M (2006) Psychosocial interventions for depression, anxiety, and quality of life in cancer survivors: metaanalyses. Int J Psychiatry Med 36: 13-34.

Pocock SJ (1983) Clinical Trials: A Practical Approach. Wiley-Blackwell: Chichester, West Sussex, UK; New York, NY, USA.

Savard J (2010) Faire face au cancer avec la pensée réaliste (Montréal) Flammarion Québec: Montréal, Canada.

Savard M-H, Savard, Simard S, Ivers H (2005) Empirical validation of the Insomnia Severity Index in cancer patients. Psychooncology 14: 429-441.

Sawni A, Breuner CC (2017) Clinical hypnosis, an effective mind-body modality for adolescents with behavioral and physical complaints. Children (Basel) 4: pii E19.

Sedgwick P (2013) What is a patient preference trial? BMJ 347: f5970.

Sherman KJ, Wellman RD, Cook AJ, Cherkin DC, Ceballos RM (2013) Mediators of yoga and stretching for chronic low back pain. Evid Based Complement Alternat Med 2013: 130818.

Smith KB, Pukall CF (2009) An evidence-based review of yoga as a complementary intervention for patients with cancer. Psychooncology 18: 465-475.

Stagl JM, Bouchard LC, Lechner SC, Blomberg BB, Gudenkauf LM, Jutagir DR, Glück S, Derhagopian RP, Carver CS, Antoni MH (2015) Long-term psychological benefits of cognitive-behavioral stress management for women with breast cancer: 11-year follow-up of a randomized controlled trial. Cancer 121: 1873-1881.

The Executive Committee of the American Psychological Association Division of Psychological Hypnosis (1994) Definition and description of hypnosis. Contemp Hypn 11: 142-162.

Tojal C, Costa R (2015) Depressive symptoms and mental adjustment in women with breast cancer. Psychooncology 24: 1060-1065.

Vanhaudenhuyse A, Gillet A, Malaise N, Salamun I, Barsics C, Grosdent S, Maquet D, Nyssen A-S, Faymonville M-E (2015) Efficacy and costeffectiveness: a study of different treatment approaches in a tertiary pain centre. Eur J Pain 19: 1437-1446.

Vanhaudenhuyse A, Laureys S, Faymonville M-E (2014) Neurophysiology of hypnosis. Neurophysiol Clin Neurophysiol 44: 343-353.

Weis J, Horneber M (2015) Cancer-Related Fatigue. Springer Healthcare Ltd.: Tarporley, England.

Zigmond AS, Snaith RP (1983) The hospital anxiety and depression scale. Acta Psychiatr Scand 67: 361-370.

This work is published under the standard license to publish agreement. After 12 months the work will become freely available and the license terms will switch to a Creative Commons AttributionNonCommercial-Share Alike 4.0 Unported License. 